\title{
Effect of Membranous Septal Length on the Risk of Atrioventricular Block in Patients Undergoing Transcatheter Aortic Valve Implantation
}

\author{
Yuki Kozai, MD; Toru Awaya, MD; Kenji Makino, MD;
}

Norihiro Kogame, MD; Yoshinari Enomoto, MD; Yoshiyuki Yazaki, MD;

Hidehiko Hara, MD; Masao Moroi, MD; Masato Nakamura, MD

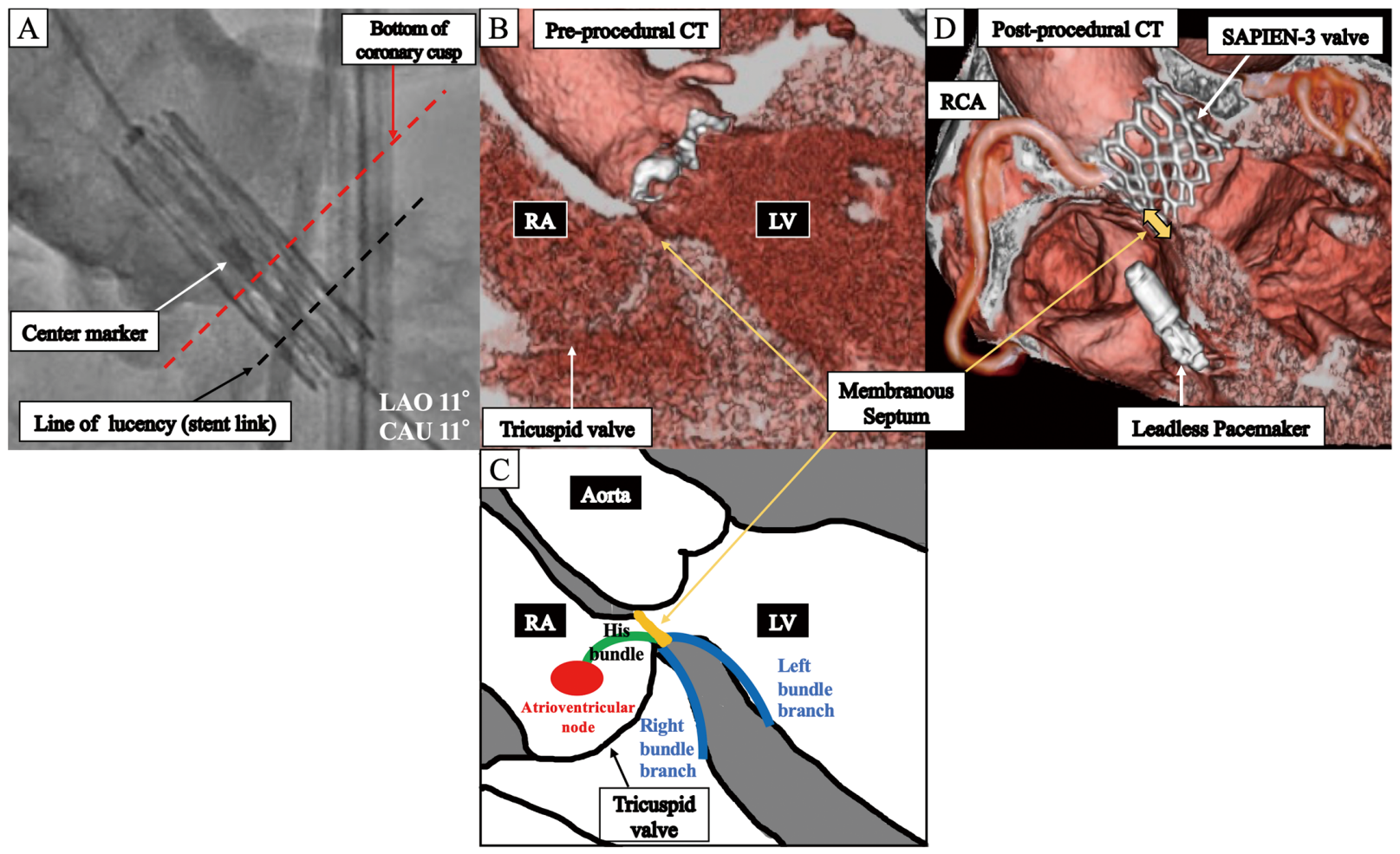

Figure. (A) A SAPIEN-3 valve was deployed slightly below the center marker in alignment with the bottom of the coronary cusp. $\mathrm{LAO}$, left anterior oblique; CAU, caudal. (B) The height of the membranous septum (MS) in this case was short (3.1 mm), as measured from the vertex of the muscular septum to the bottom of the coronary cusp. CT, computed tomography; LV, left ventricle; RA, right atrium. (C) Illustration of the anatomical conduction system. (D) The SAPIEN-3 valve was deployed deeper and overlapped with the MS. A leadless pacemaker was implanted in the right ventricle. RCA, right coronary artery.

Received November 25, 2021; accepted November 25, 2021; J-STAGE Advance Publication released online December 10, 2021 Time for primary review: 1 day

Division of Cardiovascular Medicine, Toho University Ohashi Medical Center, Tokyo, Japan

Mailing address: Toru Awaya, MD, Division of Cardiovascular Medicine, Toho University Ohashi Medical Center, 2-22-36 Ohashi, Meguro-ku, Tokyo 153-8515, Japan. E-mail: toru0228@gmail.com

All rights are reserved to the Japanese Circulation Society. For permissions, please e-mail: cr@j-circ.or.jp ISSN-2434-0790 
A 92-year-old woman with severe aortic stenosis was admitted for transcatheter aortic valve implantation (TAVI). She had no electrocardiogram abnormalities, such as right bundle branch block or atrioventricular block (AVB). A 26-mm SAPIEN-3 valve (Edwards Lifesciences, Irvine, CA, USA) was deployed by the traditional method using a center marker (Figure A) with $2 \mathrm{~mL}$ less than nominal volume because the annulus area $\left(473.8 \mathrm{~mm}^{2}\right)$ was smaller than a $26-\mathrm{mm}$ valve $\left(519 \mathrm{~mm}^{2}\right)$. After TAVI, new left bundle branch block and first-degree AVB emerged, which developed into advanced AVB on postoperative day 5. Finally, a leadless pacemaker was implanted before discharge. We retrospectively evaluated pre- and post-operative computed tomography (CT) images, which revealed that the valve edge overlapped with the membranous septum (MS; Figure B,D). The bundle of His runs along the lower end of the MS (Figure C). Therefore, we assumed that mechanical injury caused by the valve was responsible for the conduction disturbance. It has been reported that an MS length $<5 \mathrm{~mm}$ (in this case, $3.1 \mathrm{~mm}$ ) is a risk factor for pacemaker implantation. ${ }^{1}$ In the high implantation technique, the line of lucency (Figure A, black line) is aligned to the bottom of the noncoronary cusp, not the center marker, which may minimize the risk of pacemaker implantation. ${ }^{1}$

\section{Disclosures}

None.

\section{Reference}

1. Ramanathan PK, Nazir S, Elzanaty AM, Nesheiwat Z, Mahmood M, Rachwal W, et al. Novel method for implantation of balloon expandable transcatheter aortic valve replacement to reduce pacemaker rate: Line of lucency method. Structural Heart 2020; 4: 427-432. 